\title{
Esophageal Impairment During Swallowing
}

National Cancer Institute

\section{Source}

National Cancer Institute. Esophageal Impairment During Swallowing. NCI Thesaurus.

Code C127181.

An assessment of an individual's esophageal impairment during swallowing. 